\title{
Conocimiento escolar y saberes campesinos. Encuentros y desencuentros en la escuela rural ${ }^{1}$
}

\author{
Claudia Marcela Peña \\ Institución Educativa Técnica Agropecuaria de Chivatá, Colombia \\ senderovioleta@hotmail.com
}

1 Artículo de reflexión deriva de la investigación titulada: "La explicación de los fenómenos climáticos: una mirada desde la formación y prácticas de los maestros rurales en relación con los saberes campesinos." Llevada a cabo en las escuelas rurales del Municipio de Tunja-Boyacá.

2 M.Sc (c) en Educación. Universidad Pedagógica y Tecnológica de Colombia 


\section{Conocimiento escolar y saberes campesinos. Encuentros y desencuentros en la escuela rural}

\section{Resumen}

El presente artículo propone realizar una reflexión teórica acerca de la relación existente entre conocimiento y saber, desde una perspectiva epistemológica que explica el origen de cada uno, planteando una articulación entre ambos en la escuela rural. Partiendo de algunas preguntas, analizamos los fundamentos que nos guían hacia la discusión sobre si la escuela es portadora de un universo ajeno al campesino, una especie de "urbanización" de lo rural a través de ella, teniendo en cuenta que ésta es un fenómeno urbano. Desde una postura descolonialista nos preguntamos por la posibilidad de refutar los supuestos epistemológicos, que localizan la producción de conocimiento solo dentro de la academia y dentro de los cánones y paradigmas establecidos por el cientificismo occidental. En este sentido, se propone que la práctica educativa sea repensada desde el contexto rural, que tenga en cuenta y dialogue con las formas de producción de conocimiento que se generan en ámbitos extra-académicos y extra-científicos, refiriéndonos a los saberes campesinos. Hablamos de un universo que contiene ideas sobre el mundo, una cosmovisión, maneras de entender la naturaleza y su relación con el hombre, el conocimiento, la educación y el aprendizaje en el contexto campesino, que ha sido objeto del olvido por parte de la sociedad colombiana durante décadas.

Palabras clave: educación rural; conocimiento; saberes; paradigma; modernidad; campesino

\section{School knowledge and country people knowledge agreements and disagreements in the rural school.}

\section{Abstract}

This article proposes a theoretical reflection about the relationship between knowledge and expertise, from an epistemological perspective that explains the origin of each one, proposing a meeting point between the two in the rural school. Parting from certain questions, we analyze the fundamental points which guide us towards the discussion on whether the school is a carrier of a universe unrelated to the peasant, a kind of "urbanization" of the rural through it, taking into account that this is an urban phenomenon. From an anti-colonialist point of view, we ask about the possibility of refuting the epistemological assumptions that identifies the production of knowledge only within the Academy and within the canyons and paradigms established by the Western Science. In this sense, it is proposed that educational practice be thought and spearheaded from the rural context. It is here that the forms of knowledge production are taken into account and engaged in dialogue in the realm of extra-academic and extra-scientific areas that uphold the peasant's knowledge. We talk about a universe that contains ideas about the world, a worldview, ways of understanding nature and its relationship with man, knowledge, education and learning in the rural context that has been forgotten by Colombian society for decades.

Keywords: Rural education; knowledge; knowledge; paradigm; modernity; peasant.

\section{Conhecimento escolar e saberes camponeses. Encontros e desencontros da escola rural}

\section{Resumo}

O presente artigo procura realizar uma reflexão teórica sobre a relação existente entre conhecimento e saber, a partir de uma perspectiva epistemológica que explica a origem de cada elemento, defendendo uma articulação dos dois na cena rural: partindo de algumas perguntas, analisamos as bases que nos guiam na discussão sobre se a escola contém um universo diferente ao universo do camponês, considerando que ela é um fenômeno urbano. Desde uma postura decolonial, refletimos sobre a possibilidade de refutar os pressupostos epistemológicos que localizam a produção de conhecimento só no interior da acadêmia e dos cânones e paradigmas estabelecidos pelo cientficismo ocidental. Neste sentido, propõe-se que a prática educativa seja pensada de novo a partir do contexto rural, tendo em conta e dialogando com as formas de produção de conhecimento que são gerados em contextos extra-acadêmicos e extra-científicos, ou seja, os saberes camponeses. Falamos de um universo que contém ideias sobre o mundo, uma cosmovisão, modos de compreender a natureza e sua relação com o humano, o conhecimento, a Educação e a aprendizagem no contexto camponês, que foi objeto do esquecimento pela sociedade colombiana durante décadas.

Palavras chave: educação rural; conhecimento; saberes; paradigma; modernidade; camponês. 


\section{Introducción}

El interés principal de este texto es abordar el tema de la educación rural, teniendo en cuenta que en Colombia hay una escasez de estudios sistemáticos sobre el mismo, debido, tal vez, a la indiferencia generalizada que se produce en nuestro país hacia este sector, pues ha existido una tendencia a menospreciar lo campesino y a asociarlo con atraso, situación que se presenta tras considerar el modelo urbano como modelo de desarrollo. Lo anterior no es un fenómeno exclusivo de nuestro país, es un asunto común en otros países latinoamericanos que se han situado en la misma corriente, aquella que consiste en creer que el bienestar, el futuro y el progreso se asocian a un modelo industrial de base urbana.

El resultado ha sido abandonar el modelo campesino, práctica que se refleja principalmente en el ámbito educativo, y que tiene repercusiones en la actividad investigativa, en donde la escasa producción se puede explicar debido al reducido número de investigadores interesados en el tema y quizás también, debido a la invisibilidaddelcontextorural,comoalaespecificidaddelmismoenelámbitoeducativo.

La atención del texto se centra en identificar que el sector rural está diferenciado del urbano, debido a las particularidades del entorno, de la población, de las formas de vida, entre otros. Produciéndose allí multiplicidad de saberes, los cuales a nuestro modo de ver, deberían tenerse en cuenta por parte del maestro rural, desde su formación y a través de su práctica docente, para responder así a las necesidades que se presentan en el contexto y la búsqueda de una educación con mayor pertinencia social.

El origen de nuestra inquietud radica principalmente en el hecho del nulo reconocimiento de los saberes campesinos en el ámbito escolar o lo que es igual, la preeminencia del saber escolar sobre el saber campesino, se trata entonces, de un problema epistemológico trasladado a la escuela rural.

\section{Análisis del contexto rural}

\section{Lo rural}

La ruralidad tuvo importancia hace 60 años, cuando Colombia era un país agrícola y la mayoría de su población rural. Debido a que esto declinó, paralelamente el interés social por el tema se redujo. Ahora, las fronteras entre la ciudad y el campo 
son cada vez más borrosas, lo que incrementa la dificultad de circunscribir lo rural y diferenciarlo de lo urbano, razón por la cual el contexto rural ha carecido de identidad y de propuestas orientadas a responder sus problemáticas. La categoría misma de educación rural carece de reconocimiento, mucha gente prefiere hablar de "educación para lo rural" y con ello se elude el problema y se está ausente de todo compromiso con el término educación rural (Zamora, 2010). Buena parte de los pocos estudios existentes sobre el tema tienen una orientación más bien sociológica y política, hay pocos aportes desde la pedagogía, es decir que es incipiente el aporte de los maestros en el tema (Zamora, 2010).

Las propuestas para la educación rural se reducen a un planteamiento que tiene que ver con los modelos pedagógicos. Hay experiencias pedagógicas en educación rural, en su mayoría con escasa difusión, al interior de las instituciones, basadas en experiencias e iniciativas como el caso de los proyectos de aula, elaborados al margen de un proceso investigativo cuyos resultados, en mayor parte, únicamente trascienden los límites inmediatos. Por lo anterior, podemos pensar que los maestros rurales "crean cosas" que quedan en la formulación oral y permanecen inéditas.

\section{Una educación y una escuela hegemónica}

Entendemos la educación como el proceso social de transmisión y apropiación de saberes, considerando que de acuerdo a las diversas sociedades, se crean diferentes andamiajes conceptuales para que las nuevas generaciones asimilen prácticas, valores y principios (Pulido, 2007).

En este sentido, consideraríamos la educación como el vehículo idóneo para construir, reconstruir y perpetuar los saberes de las culturas. Sin embargo, las cosas se han dado de manera unilateral, debido a que se ha impuesto la cultura eurocéntrica hegemónica, sobre las particularidades individuales y colectivas de los grupos sociales.

Situándonos en Latinoamérica, sabemos que la educación ha sido subordinada al paradigma educativo occidental, y tal como lo plantea Althusser (1989) nos hemos encontrado bajo siglos de dominación en los que hemos aceptado las estructuras capitalistas existentes como el modelo imperante. Siendo la escuela el medio que ha contribuido a la reproducción de la sociedad, al transmitir, a través de los contenidos escolares, las materias que nos hacen ver el orden social como bueno y deseable (Da Silva, 2001).

Continuando con la misma idea, Bourdieu (2005), demuestra cómo desde el punto de vista de la institución, todo está dispuesto para el triunfo escolar de las clases privilegiadas que poseen la "gran cultura". También afirma, que existe una cultura y una clase dominante, legitimadas socialmente por su prestigio y valor. En ese sentido, la escuela actuaría como un mecanismo de exclusión por parte de la cultura 
dominante hacia la cultura dominada, utilizando el currículo como dispositivo que se expresa a través del código cultural dominante, es decir que para los niños de clases dominadas este código es indescifrable, razón por la cual, estos son conducidos al fracaso, a través de un proceso de reproducción cultural, que permite garantizar tanto el proceso de reproducción social, como el de las relaciones de clase existentes.

De este modo, la escuela contribuye a reproducir la estratificación social y legitimarla, asegurando su interiorización y persuadiendo a los individuos de una naturalización de las relaciones sociales, noción mediante la cual la eficacia del pensamiento científico moderno se efectúa a partir de la sociedad liberal industrial, que a su vez se constituye en el orden social deseable y el único lugar posible. Así pues, nos encontramos con sociedades sin ideologías, un modelo civilizatorio único, globalizado, universal, que considera la sociedad de mercado como la única opción posible, como el fin de la historia (Lander, 2000).

Dentro de ese orden de ideas, el maestro no desarrollaría un rol personal y carismático como se tiende a creer, sino que sus acciones derivarían de la autoridad legítima "la escuela", de la que es agente y la cual esta investida de la función social de enseñar, y por esto mismo, de definir lo que es legítimo aprender. Por esta razón, la escuela hace propia la cultura particular de las clases dominantes, enmascara su naturaleza social y la presenta como la cultura objetiva, indiscutible, rechazando al mismo tiempo las culturas de los otros grupos sociales, como es el caso de la cultura campesina, legitimando de tal forma la arbitrariedad cultural (Bourdieu, 2005).

En contraposición a las formas de reproducción, surge la teoría crítica y la educación popular como respuesta a las formas tradicionales y positivistas de entender la producción de conocimiento. En América Latina se desarrolló la corriente crítica desde los inicios de la independencia, con pensamientos que plantearon la educación popular: (Simón Rodríguez) de universidades populares y Marxismo indoamericano: (José Carlos Mariategui), educación propia: (Lizardo Pérez) y educación liberadora: (Paulo Freire). Dando forma a lo que se ha denominado el paradigna educativo latinoamericano, basado en la educación como cultura y contexualmente situada y la pedagogía como un proceso educativo de relaciones sociales y políticas, más allá y no solo en el ámbito de la escolardidad (Mejía, 226).

La educación popular se constituye en una corriente de pensamiento y acción dentro del campo de las ciencias sociales, particularmente de la pedagogía, el trabajo comunitario y los estudios culturales, que se ha ido desarrollando dentro del ámbito de quienes estudian, investigan y se dedican a coordinar proyectos y programas de lo que hoy conocemos como lo popular. Es parte de una epistemología de estudios culturales y comunitarios, por lo que incluye y presupone aspectos metodológicos, técnicas y métodos. Es una concepción epistemológica de carácter dialéctico que cuestiona el paradigma positivista, cuya propuesta metodológica, 
pedagógica y didáctica se basa en la participación, en la integración y en el diálogo y reconocimiento de diferentes saberes (Delgado, 2011).

El planteamiento esta dirigido hacia la diversidad de conocimientos, de epistemes, prácticas, movimientos sociales, la existencia de grupos originarios afros, mujeres y minorías sociales y sexuales, quienes niegan la pretendida universalidad epistémica euronorteamericana. Desde esas singularidades se plantean preguntas a la universalidad, para dar forma a historias y epistemes por donde emerge lo otro no eurocentrico, como forma de alteridad que cuestiona el poder presente allí y que niega la singularidad.

Es precisamente en este proyecto ideológico alternativo, de corte liberador y emancipador para los individuos, especialmente para los más desfavorecidos, donde queremos enmarcar nuestro estudio.

\section{La escuela rural en Colombia}

Para comprender la escuela rural en Colombia, es necesario tener en cuenta los hechos históricos comprendidos desde la primera mitad del siglo XX, que nos develan la realidad política y social del país, que desataron con mayor fuerza la situación de violencia en gran parte del territorio y cuyo desarrollo y efectos, determinó en gran medida el desarrollo y la manera de ser de la educación y la escuela rural.

Durante la primera mitad del siglo XX aparecen dos conceptos hegemónicos que fueron determinantes al momento de pensar la escuela: la noción de progreso y la de higiene, que estaban ligadas a la necesidad de urbanizar las ciudades, para así superar las condiciones imperantes y elevar los estándares de vida de las personas. Esta corriente implicó el disciplinamiento de la sociedad, a partir de unas nuevas maneras de comportarse, organizarse y relacionarse que procedían de ideas positivistas fundadas en la razón, dando paso al discurso de la modernidad en tanto se concibió a la misma como la forma de vida deseable y última. Paralelo a este proceso desarrollista que germinaba en las ciudades, se encontraba el territorio rural, con procesos diametralmente opuestos y padeciendo fuertes golpes de violencia, producto de enfrentamientos entre liberales y conservadores, que influyó en la manera de habitar y pensar el mundo en aquel escenario inhóspito y olvidado.

Fue tras el Gobierno del General Rojas Pinilla (Cuervo, 1995), que el desarrollo llegó al campo, mediante la construcción de carreteras, tecnificación e industrialización de lo rural, sistema de salud y escuelas que fueron pensadas a partir de la idea de escuela urbana. En ese contexto analítico, el campesino fue concebido como el sujeto que vive bajo la influencia de creencias mágicas y religiosas, tradicionalismo familiar e incipiente relación con el concepto de educación, del cuidado del cuerpo y escasas habilidades comunicativas, que le impedían configurarse como sujeto activo dentro del proyecto desarrollista. 
En este sentido es donde entra la escuela rural a desempeñar el papel transformador de una sociedad agrícola incipiente, inculta, tosca y analfabeta. Así, la escuela fue pensada desde una visión de adoctrinamiento político, una necesidad de civilizar y de mantener el orden en épocas de violencia. Paralelamente, desde las políticas nacionales se direccionaron una serie de aspiraciones a cumplir en el sector rural a través de la escuela, estas apuntaban a ofrecer al campesino unos conocimientos mínimos que contribuyeran al mejor cuidado de los niños y adultos, a la optimización desde el punto de vista económico de las cuestiones de trabajo agrario, a fomentar el espíritu patriótico que tan perturbado se hallaba por aquellas épocas en esos sectores sociales y finalmente a la superación cultural (Acosta M. , 2010).

En ésta época surgieron nuevos mecanismos utilizados para la educación del campesinado, tales como las escuelas primarias, escuelas de mayordomos, normales superioresdeeconomíadomésticayescuelasradiofónicas, porejemploRadioSutatenza, que buscaba alfabetizar a los campesinos, superando los obstáculos de tiempo y espacio, dejando de lado la lógica y organización propia del sistema de enseñanza en la escuela, con aulas cerradas, horarios establecidos y sistemas de evaluación.

\section{La escuela rural del siglo XXI}

Actualmente, los estudios sobre la escuela rural se han enfocado en analizar estructuralmente la misma, trabajando elementos que la componen y centrándose en las comunidades que sirven al proceso educativo en ellas, priorizando su análisis en sus carencias: de agua potable, energía eléctrica, vías de acceso, estrategias de mercadeo y de unos precios más justos para los productos de su economía. También se habla sobre la importancia de ofrecer además de cobertura educativa, una mayor pertinencia y experiencias significativas en educación, para que las personas del área rural logren superar las desfavorables condiciones socio-económicas en las que se encuentran (Coley, 2008). En este sentido, vale la pena emprender propuestas pedagógicas pensando en la gente, no en el cemento, tampoco en la tubería, ni siquiera en el suelo, el agua, la vaca, el árbol, tal como señala (Crespo, 2006).

Sin embargo, las políticas de gobierno, dirigidas desde el Ministerio de Educación Nacional, están formuladas a partir del concepto de desarrollo sostenible, en el sentido en que la población rural pueda acceder a bienes y servicios básicos, entre los que se encuentra la educación, desde el punto de vista de capacitar técnicos y tecnólogos agropecuarios competentes, lo cuál a su vez, acontribuirá a combatir la pobreza y el hambre en el sector rural (Novoa, 2013).

Nos interesa remarcar que la escuela rural se encuentra en un espacio vinculado estrechamente al territorio, el cual se caracteriza porque tiene precisamente identidad propia. Sus habitantes forman parte de un colectivo social con códigos culturales concretos, léxicos y símbolos característicos, costumbres diferentes 
(gastronomía, artesanía, experiencias musicales, etc.). Así, el estudiante rural suele manejar una cultura diferente a la de la escuela, los libros de texto y evidentemente el maestro. En la escuela no se aprovechan sus experiencias, sus vínculos familiares, sus conocimientos de los lenguajes silenciosos; nada de eso es valorado desde el discurso pedagógico urbano, al contrario, se imponen currículos propios de la ciudad, donde se rompe con los valores y sentimientos de pertenencia a un territorio.

Algunos interrogantes que planteamos frente a la educación rural en Colombia son: ¿qué calidad y pertinencia tiene la educación que reciben los niños campesinos?, ¿existe una educación rural para las escuelas rurales?, ¿existe una formación de maestros para la escuela rural? onsideramos que los mismos programas escolares que se diseñan para la ciudad, son trasladados al campo, por lo que se presta una educación descontextualizada y de escasa pertinencia curricular que forma hombres para los grandes centros de producción y de consumo.

Si se observa en retrospectiva el lugar y la función de la escuela rural, podemos hallar gran ambigüedad en su papel, en tanto esta "ha difundido, es verdad, unas formas culturales pensadas por y para el medio urbano, y sin embargo, no ha sido capaz de difundirla suficientemente, ni de procurar a los alumnos de las zonas rurales, los conocimientos adecuados para que se hallaran en condiciones de igualdad, respecto a los jóvenes de zonas urbanas" (Zamora L. , Sobre el quehacer de los docentes rurales, 2005, pág. 5).

Frente a esta paradoja, nuestro interés se centra en develar en los encuentros y desencuentros escolares, los contenidos y procedimientos del saber escolar, con la experiencia que los niños adquieren en su medio social. Se trata de acercar la cultura escolar a los intereses, habilidades y experiencias locales.

\section{La noción de campesino}

Autores como EricWolf(1972) Hamza Alavi (1974) y Eric Hobsbwam(1976), a partir del análisis de los casos de la revolución rusa, china e india, sostienen que los campesinos son la clase menos militante, debido a sus hábitos serviles y su mentalidad atrasada. Más adelante el antropólogo James Scott (1985) y Edward Thompson (1989) inscribieron sus desarrollos teóricos en la relación dicotómica: "cultura contra economía", desde el abordaje de las rebeliones campesinas y descentrando la atención del concepto de clase propio del determinismo económico, por el de conciencia de clase, entendida desde el modo en que se expresan las experiencias en términos culturales: tradiciones, sistemas de valores, ideas y formas institucionales (Barbetta, 2012).

Lo anterior nos conduce a pensar que el concepto de campesino históricamente ha estado relacionado a la producción agrícola, es decir desde una mirada economicista 
del tema y desde la perspectiva de la imposibilidad de ascender en la escala social, debido a su sometimiento a determinadas formas de dependencia y la explotación por parte de las clases dominantes que se apropian de sus excedentes (Sevilla, 2012). Por esta razón a partir de 2013, en Colombia se han desatado una serie de protestas y manifestaciones a nivel nacional despertándose otro tipo de consciencia social, que rechaza mecanismos imperialistas de sometimiento como los TLC y apoya a las comunidades campesinas y su lucha por superar las incipientes condiciones de vida.

\section{La relación entre conocimiento y saber, un problema de carácter epistemológico}

Uno de los problemas que más ha resaltado en la dinámica educativa de las escuelas rurales (y no rurales), ha sido la tendencia generalizada a impartir contenidos de enseñanza, que han sido transferidos a partir de propuestas curriculares externas, y conocimientos producidos "desde afuera". La relación de lo anterior con la producción de saber que nace al interior de la cultura campesina, constituye el eje central de análisis de nuestro estudio, el cual se desarrolla a partir de la posible relación existente entre conocimiento científico y saberes campesinos, dentro del contexto rural.

\section{Los saberes campesinos}

Coincidimos con Barbetta y su fundamentación en las teorías que cuestionan el carácter colonial-eurocéntrico y la idea de modernidad como modelo civilizatorio universal. Su crítica se orienta hacia la crisis del paradigma dominante, y hacia el modelo de racionalidad que preside la ciencia moderna, y las implicaciones que esta forma de conocer y comprender tienen sobre la realidad social, política y económica (Barbetta, 2012). Este propone replantear los mecanismos de comprensión del campesinado, a partir del estudio de sus saberes, sus prácticas, sus fragmentos epistemológicos, sociales, económicos, para pensar otros modos de comprensión de la realidad, planteando el debate sobre el campesinado desde la mirada crítica y desde la perspectiva de la colonialidad del poder.

En ese sentido, señala la paradoja que a finales del siglo XIX y principios del siglo XX, se presentó con relación al estudio del campesinado, tema que se tradujo en el problema de la cuestión agraria, y que fue abordado por investigadores como Marx, Lenin, Kautsky, entre otros. Lo curioso o inquietante radica en que han sido estudios realizados desde Europa y Norteamérica, los cuales se hallan muy lejos de la realidad de los países periféricos, quienes constituyen hoy día el mayor referente para los estudios sobre el "campesinado". No obstante, a pesar de existir otros estudios, estos siguen siendo los más divulgados. 


\section{La episteme tradicional}

En la tradición del conocimiento, se ha producido una mirada que señala el conocimiento científico como el que por sus características de control, rigor y verificabilidad, posee una legitimidad incuestionada, lo que ha permitido que se coloque como superior a otras epistemes, incluso de manera universal.

Dicha categoría, le ha permitido sobreponerse a lo singular y lo particular, convirtiéndose en el tipo de pensamiento que se desarrolló durante la modernidad y que constituyó el paradigma del conocimiento basado en lo teórico. Sus fundamentos, conducen a un desprecio por la acción y la práctica no estructuradas, bajo postulados científicos a la manera de experiencias de laboratorio. En consecuencia, se entiende el concepto de acción como una manera pobre y menor de la reflexión y análisis, los saberes de la práctica y los populares como los "incultos" por su falta de rigurosidad, su limitación en el tiempo y en el espacio, por ser de carácter local y cuestionados como formas de saber que se alejan del conocimiento.

En tiempos pasados, Rousseau planteó en su discurso sobre las ciencias y las artes (1750) las siguientes cuestiones: ¿el progreso de la ciencia y de las artes contribuirá a purificar o a corromper nuestras costumbres?, ¿hay alguna relación entre la ciencia y la virtud?, ¿hay alguna razón de peso para que sustituyamos el conocimiento vulgar que tenemos de la naturaleza y de la vida y que compartimos con los hombres y las mujeres de nuestra sociedad por el conocimiento científico producido por pocos e inaccesible a la mayoría? Rousseau respondió de modo simple con un rotundo no.

Más de doscientos años después nuestras preguntas son las mismas, estamos de nuevo colocados sobre la necesidad de pensar en la relación entre ciencia y virtud, por el valor del conocimiento vulgar u ordinario que los sujetos creamos y usamos para dar sentido a nuestras prácticas y que la ciencia se obstina en considerar irrelevante, ilusorio, falso. $Y$ tenemos que preguntar, también, por el papel de todo el conocimiento científico acumulado en el enriquecimiento o empobrecimiento práctico de nuestras vidas, es decir por la contribución positiva o negativa de la ciencia a nuestra felicidad (De Sousa, 2009).

\section{Cuestionamientos a la epistemelógica racional}

El positivismo lógico reconocido en el circulo de Viena como el conocimiento valido para la ciencia, por ser de tipo teórico y matematizado, obtenido mediante el método hipotético-deductivo a partir de la experimentación, se consolidó como la única opción de racionalidad científica por asegurar un conocimiento obtenido de manera rigurosa y experimental. 
A lo largo del siglo XX este modelo comenzó a tener serios cuestionamientos, por parte de autores como Popper, Lakatos, Wittgenstein, la Escuela de Frankfurt y más adelante Kuhn. Dichos cuestionamientos van dirigidos desde la consideración de la ciencia y su método, como posibilidades que no logran alcanzar la verdad, y de la imposibilidad de alcanzarlo todo, pues los seres humanos no somos completamente racionales y aun cuando actuemos racionalmente, cabe que tengamos una falsa teoría sobre nuestras propias acciones racionales (Lakatos, 1968).

Thomas Kuhn explica la evolución de la ciencia desde un enfoque historicista, afirmando que ésta no se desarrolla a partir de un mismo patrón aplicable a lo largo de distintas épocas; es decir, que los contextos históricos son determinantes en la configuración de dicha actividad, existiendo así otras teorías que han pasado de moda o que se encuentran fuera del paradigma científico, las cuales, aunque hayan sido descartadas, no dejan de ser científicas (Kuhn, 1975).

Wittgenstein, por su parte hace referencia a los juegos del lenguaje, como el lugar en que se construye la esencia de la realidad, que se produce desde diversos modelos de representación: el arte, la música, la literatura, la historia, cuyos lenguajes implican prácticas, imaginarios y modos de ser que nos conducen a pensar que están inmersos en sistemas simbólicos y contextos determinados (Tamayo, 2013). De allí que planteemos dentro de la lógica discursiva que citamos, comprender que el conocimiento se mueve hoy desde el punto de vista de la multiplicidad, la cultura local, los saberes populares, las particularidades y singularidades.

Así, ha existido una tendencia hacia el estudio de las teorías denominadas como científicas, por encima de las "creencias", saberes populares, idiosincrasia de los pueblos, que han quedado relegados del campo de la ciencia. Esto es discutible hoy en día, pues se comprende que dichas teorías no deben ser descartadas o rechazadas, lo cual se constituye en una "revolución historiográfica" en el estudio de la ciencia, que aún está en sus etapas iniciales y ha cobrado fuerza en lugares como Latinoamérica, debido a propuestas como la educación popular.

\section{Ciencia con contexto e historia}

De acuerdo al reconocimiento de dichos factores históricos y sociales que median la construcción del conocimiento científico, se generaron nuevos procesos de producción de conocimiento, orientados no solo a la explicación del mundo, sino al abordaje de este como un tipo de actividad humana, como cultura compleja y difícil de describir. Esto condujo a un encuentro entre la ONU y la UNESCO realizado a finales de los años 80, donde se comenzó a hablar del modo dos de la ciencia, que Ilevó a replantear el entendimiento positivista y determinó nuevos aspectos a tener en cuenta: la historicidad, los contextos de producción, aplicación y la necesidad de implicarla en la solución de los problemas de la humanidad. A partir de allí, 
autores como Chalmers formulan una revalorización de la naturaleza de la ciencia y sus métodos. Hablando de racionalidades fuertes y comenzando a referirse a una racionalidad moderada y contextual (Chalmers, 1987).

\section{El cambio paradigmático}

Retomando las ideas de los apartados anteriores, en donde se resalta la existencia actual de una crisis muy profunda de la teoría eurocéntrica, donde vale la pena resaltar para nuestro análisis la manera en que conceptos como los derechos humanos, la democracia y el desarrollo han impedido alternativas reales al capitalismo. Según algunos pensadores, el concepto sobre "desarrollo" se creó para que la mayoría de pueblos del mundo, sean considerados como subdesarrollados. Y esta consideración hace énfasis en la economía, pero además en sus instituciones, leyes, costumbres y filosofías (Santos, 2009).

También podemos hablar de la existencia de una conexión estrecha entre geografía, política, cultura y conocimiento que se ha consolidado a partir de las naciones del norte sobre las naciones del sur. En efecto, el conocimiento forma parte integral de la construcción y organización del sistema-mundo moderno que aún es colonial, es decir, que la historia del conocimiento está marcada geo-históricamente, geo-políticamente y geo-culturalmente y tiene valor, color y lugar de origen.

Un ejemplo de lo anterior lo hallamos en Kant, para quien la raza blanca era la única apta para el progreso en cuestión de educación. Este autor dio al conocimiento un lugar y además un color. Así, la colonialidad del poder ha pasado al campo del saber, descartando la intelectualidad indígena y afro e instalando el eurocentrismo como única alternativa del conocimiento. De igual forma, la manera como la modernidad creo la ilusión de que el conocimiento es abstracto y deslocalizado, nos hizo pensar que es algo universal, que no tiene casa, género o color (Walsh, 2005).

Finalmente, sobre la posibilidad de que diferentes formas culturales de conocimiento, puedan convivir en el mismo espacio, Santiago Castro responde a la cuestion con su propuesta basada en la transculturización del conocimiento. Afirma el autor, que este diálogo de saberes ha sido casi imposible hasta el momento porque el modelo epistémico del punto cero (paradigma occidental) se ha encargado de impedirlo. Observados desde el punto cero, los conocimientos que vienen ligados a saberes ancestrales o tradiciones culturales lejanas o exóticas, son vistos como doxa, es decir como un estado que debe ser superado. Solamente son legitimos, aquellos conocimientos que cumplen con las carácterísticas metodológicas y epistémicas definidas a partir del punto cero. Los demás conocimientos, desplegados historicamente por la humanidad durante milenios, son vistos como anecdóticos, superficiales, folclóricos, mitológicos, "pre-científicos" y en cualquier caso, como perteneciente al pasado de occidente (Castro, 2007). 
En respuesta a la pregunta sobre ¿cómo es posible el diálogo de saberes?, Castro menciona que el diálogo de saberes solo es posible a través de la descolonización del conocimiento y la descolonización de las instituciones productoras o administradoras del conocimiento. Así pues, descolonizar el conocimiento significa descender del punto cero y hacer evidente el lugar desde el cual se produce ese conocimiento. La ciencia estableció que entre más lejos se coloque el observador del objeto de estudio, logrará la objetividad del conocimiento. El desafío de ahora es el de establecer una ruptura con ese pathos de la distancia. Es decir que ya no es el alejamiento, sino el acercamiento el ideal que debe guiar al investigador de los fenómenos naturales y sociales (Castro, 2007, pp.89).

Por otra parte, Mignolo construye el concepto de paradigma otro como alternativa a dicha hegemonía paradigmática. Este consiste en aquel pensamiento crítico y utópico que se articula en todos aquellos lugares en los cuales la expansión colonialimperial le negó la posibilidad de razón, de pensamiento y de pensar el futuro. Su hegemonía será la de la diversidad como proyecto universal, y no la hegemonía del universal abstracto, que continúa perpetuando la colonialidad.

Un paradigma otro es distinto de la transición paradigmática que argumentó Boaventura de Sousa Santos, aunque ambos surgen de la misma corriente: el agotamiento del proyecto de la modernidad. La propuesta de un paradigma otro muestra la opción de pensar el conocimiento como geopolítica, en vez de pensarlo como un lugar universal al que todos tienen acceso, pero del que desafortunadamente solo unos tienen las Ilaves. El prejuicio que asume la superioridad de ciertos conocimientos sobre otros, es un escollo que ha de superarse por quienes trabajan en las oficinas del saber superior y por quienes trabajan en las oficinas del saber subalterno (Mignolo, 2003).

Un paradigma otro, emerge en y desde las perspectivas de las historias coloniales, en el conflicto entre las lenguas, los saberes y los sentires, desde las historias locales a las que les es negado su potencial epistémico y en el mejor de los casos le fueron reconocidos como "conocimiento local".

Por otra parte, se encuentran otras propuestas como la del movimiento indígena ecuatoriano denominado: modelo educativo de formación científica intercultural. Esta, apunta a la interculturalidad como proyecto epistémico que interviene en diversos campos, entre ellos el del conocimiento. Es la iniciativa de una nueva apuesta en relación con el saber, que se dirige a enfrentar y transformar los diseños coloniales que han posicionado el conocimiento de los pueblos indígenas como saber no moderno y local, al frente de la universalidad y no temporalidad del conocimiento occidental, cuyo objetivo es construir una interrelación de saberes de culturas con saberes occidentales. 
Dentro de las reflexiones entorno a la colonialidad y a la crisis del eurocentrismo como perspectiva de conocimiento, Anibal Quijano describe la manera en que las poblaciones colonizadas fueron sometidas a la más perversa alienación histórica, a través de la colonización cultural. Tanto "indios", como "negros" fueron obligados a la imitación, a la simulación de lo ajeno y a la vergüenza de lo propio. Sin embargo, fue inevitable que aprendieran a subvertir todo aquello que tenía que aprender y venerar, a través de sus modos de resistencia mediante las expresiones de sus experiencias subjetivas en torno al arte y las experiencias visuales y plásticas. Fue así como aprendieron a dar significado y sentido nuevos a los símbolos e imágenes ajenas mediante la inclusión de lo propio (Quijano, 1998).

\section{Acerca del conflicto entre conocimiento y saber}

En palabras de Marco Raúl Mejía, a partir de la educación popular es indispensable la reflexión en torno a las relaciones saber-conocimiento y la manera como allí se ha construido el entramado de occidente, donde el conocimiento corresponde a la esfera de lo científico y el rigor; en cambio, el saber estaría más en las condiciones de la práctica y pertenecería a un campo mucho menos riguroso que el planteado en la esfera del conocimiento. Por eso, abordar una búsqueda de cuáles son las epistemologías de los saberes, significa construir una reflexión desde otro lugar que nos permita un diálogo crítico entre los procesos que se generan en el saber y los que se dan en el conocimiento. En este sentido tendríamos que preguntarnos entre otras cuestiones ¿mediante qué procesos dichos saberes son inteligibles y comunicables? ¿cómo son las relaciones entre producción de saber y producción de conocimiento?.

La educación popular plantea algunas respuestas desde la tensión entre lo pedagógico y lo político y su objetivo de construir un mundo sin exclusiones, una pedagogía emancipadora, por medio de la cual se formulen cambios desde el contexto, y tomar decisiones como puede ser trabajar mas allá del PEI (Proyecto Educativo Institucional) y construir el PEC (Proyecto Educativo Comunitario), como un proyecto de empoderamiento, participación y organización popular (Mejía, M. 2001) debe constituir parte de la agenda dentro de la transición paradigmática que plantean las teorías contemporáneas, la construcción de la especificidad de la educación rural, tal como se planteó dicha construcción para el caso latinoamericano, durante el proceso de desarrollo de la globalización, pensando un proyecto desde el sur, desde las propias características culturales, desde la articulación de redes colectivas de construcción de pensamiento y acción (Mejía, M. 2004)

\section{Incidencia en la educación rural}

Paralelo a la discusión anterior, se produce el cuestionamiento sobre la incidencia de la manera como esa concepción de racionalidad de la ciencia, ha marcado el proceso educativo y escolar, y en ese sentido es que comienzan a aparecer estudios 
que replantean las formas de enseñanza de las diferentes disciplinas, formulando una manera de enseñar a través del trabajo por procesos y no por transmisión de conocimientos descriptivos. Se formula, entonces, la idea de ofrecer mayor importancia a las relaciones entre teorías, vida cotidiana y los hechos, lo cual genera un tipo de trabajo mucho más experimental.

Entendemos que existen prácticas o posibilidades constitutivas del saber que se forman a partir de relaciones entre lo sabido y lo vivido, entre lo real y lo imaginado, a partir de relaciones intersubjetivas y a partir de otras lógicas, cosmovisiones y lenguajes propios de los procesos culturales. Es en ese sentido que nuestro trabajo adquiere una real importancia, en el propósito de buscar nuevas formas, conceptos y propuestas para comprender el cambio que se ha venido gestando en la manera como se produce saber y conocimiento, y es a partir de allí, que queremos dar cuenta de estas nuevas realidades.

Dentro de la discusión es importante mencionar los aportes de Silvio Sánchez Gamboa, su reflexión se centra en establecer la tensión existente entre saberes y conocimientos y entre el conocimiento científico y el conocimiento escolar. Como es sabido, los contenidos escolares, presentan al estudiante una visión limitada y distorsionada de la ciencia, pues en su afán de ofrecer respuestas a los problemas de conocimiento, ha olvidado los orígenes de la pregunta, que constituyen la historia y la evolución de los conocimientos y de la ciencia. Afirma que los conocimientos escolares no pueden limitarse a consultar respuestas ya establecidas (gracias a la sociedad del conocimiento), sin detenerse a pensar en la formulación de preguntas generadoras de conocimiento, que busquen la resolución de problemas reales y la transformación social (Sánchez, 2010).

Según Sánchez Gamboa, la escuela ha maltratado el conocimiento científico, pues la traducción de la ciencia por medio de los libros de texto, olvida las preguntas que han generado los conocimientos y se limita solo a ofrecer al estudiante las respuestas de los mismos. Se torna interesante analizar como se traduce el conocimiento científico, por medio de los libros de texto, la mediación del maestro y a la vez, estudiar la manera en que esta mediación estaría afectada por otras formas de conocer, propias de los saberes campesinos, los cuales deben incidir en las prácticas educativas de la escuela rural.

\section{El conocimiento escolar}

Existen problemas del quehacer cotidiano, aquellos que se enmarcan en el quehacer diario de cada individuo y tienen como objetivo la actuación en su realidad humana. Por otra parte existen problemas que son considerados científicos, pues se enmarcan en las teorías y marcos conceptuales característicos de la ciencia, centrándose en la descripción y explicación de la realidad. La idea de la separación 
entre conocimiento científico y conocimiento escolar no es tan tajante, pues existe una dinámica similar en ambos conceptos, teniendo el conocimiento científico sus orígenes en el conocimiento ordinario de cada individuo, tanto en el que se refiere al proceso histórico de construcción de la ciencia como a la génesis personal del saber. Todo ello nos permite considerar, en el medio escolar, formas de conocimiento "intermedias" y aproximaciones graduales desde el conocimiento cotidiano al conocimiento científico (García E. , 1995).

Lo señalado anteriormente nos conduce a afirmar que existe un saber escolar que se nutre de las aportaciones del saber cotidiano y el saber científico. El Primero correspondería a las concepciones del alumno y el segundo estaría determinado en gran medida por las interpretaciones que el profesor realiza de este. Existen algunas diferencias entre estos dos tipos de conocimiento, para el caso podemos mencionar que el conocimiento cotidiano se caracteriza por tener su funcionalidad a partir de la necesidad de resolver problemas de orden cotidiano, de acuerdo a los intereses personales, además de ser un saber que se encuentra ligado a la acción y se produce de manera asistemática y poco organizada. En relación con los conceptos de este orden, podemos decir que son de carácter ambiguo, basados generalmente en creencias que no son comprobables.

El conocimiento científico se diferencia del cotidiano en la medida en que busca dar explicación de la realidad desde una visión distanciada, desde el ejercicio de la reflexión y superando las contradicciones para llegar al consenso entre los conflictos, inquiriendo una coherencia lógica del saber validada en una comunidad científica.

Retomando las ideas iniciales, la ciencia enseñada en la escuela difiere sustancialmente del conocimiento científico y al mismo tiempo, se distancia del conocimiento cotidiano que el niño aprende en su comunidad o entorno social. Este último es particularmente resistente al cambio, pues responde a una importante función adaptativa y no esta concebido para ponerse a prueba, siendo su afán el de responder a urgencias del entorno. Sin embargo, es inadecuado pretender que el alumno sustituya el pensamiento cotidiano por el escolar, puesto que ambos pueden coexistir, no obstante tengan un campo epistemológico de origen diferente.

En este orden o marco de reflexión, resulta pertinente articular los siguientes cuestionamientos: ¿es erróneo el conocimiento cotidiano, siendo a su vez útil y funcional en su ámbito de actuación?, ¿es acertada la pretensión de sustituir el conocimiento cotidiano por el conocimiento científico o integrar ambos en uno solo?, ¿Cuáles son los mecanismos por medio de los cuales se configura el conocimiento escolar y que papel desempeña el maestro en este proceso? 


\section{La epistemología de los saberes}

Podríamos pensar que estos tipos de conocimiento no se diferencian necesariamente en sus contenidos, sino en la epistemología constitutiva y los escenarios socioculturales en los que se producen. El conocimiento escolar tiene un nivel de análisis más complejo que el conocimiento cotidiano, pues este no es pensado para responder a preguntas que buscan la aproximación a la verdad, sino desde la necesidad de producir transformaciones en el mundo real, por lo tanto no se traduce en teorías exactas, ni se ajusta al nivel normativo que se exige por parte del maestro y su epistemología escolar, únicamente busca emprender planes de acción en relación con el entorno físico y social. En cuanto a la construcción del conocimiento cotidiano, este se da de manera implícita, es decir que opera sin que las personas tengan conciencia de su presencia. Las teorías se develan de manera individual y se socializan de forma verbal, sin seguir un modelo de comprobación de hipótesis.

Es así, como el niño y el adulto construyen su conocimiento cotidiano, antes, durante y después de su formación escolar, el cual avanza con la escolaridad porque este presenta un sentido en la cotidianidad y funcionalidad en el diario vivir. Por eso, cuando el niño llega a la escuela, trae consigo un conocimiento previo utilizado en la construcción del conocimiento escolar, impulsado por el maestro con la pretensión en algunos casos de ser reemplazado (Rodrigo M. ,2012).

A partir de allí, es interesante analizar la relación entre los saberes y el campesino para lograr comprender la construcción del conocimiento escolar, sobre la idea que éste toma forma a partir de los conocimientos cotidianos que el niño lleva consigo a la escuela. Este análisis permitiría una comprensión mayor del sujeto campesino, más allá de su vinculación con la estructura agraria y la tierra. Y es importante indagar acerca de los saberes, pese al desprestigio que históricamente ha presentado por parte de la maquinaria modernizadora, que se implementó desde el período de la posguerra y que se perpetuó hasta nuestros tiempos, pues ha sido ese saber y la forma de producirlo, el que le ha permitido existir e incorporarse a la sociedad. 


\section{Reflexiones finales}

En tiempos de cambio, en momentos de despertar colectivo y de revaloración de lo cultural y de las identidades, la mirada hacia el campo o el sector rural en Colombia, requiere la reflexión y el compromiso por parte de todos y cada uno de los actores sociales, especialmente de los educadores y maestros que desempeñan su labor en dicho contexto. La tarea más importante en el campo de la educación y la pedagogía consiste en despertar interés en iniciar la empresa de construir la especificidad de la educación rural, partiendo de la comprensión de la idea que plantea la existencia de diferencias abismales y características particulares que distancian de manera importante la cultura campesina, las comunidades rurales y la escuela rural de la sociedad urbana, las instituciones educativas propias de la ciudad y las formas de relación que allí se producen, no obstante los procesos de globalización e hibridación cultural de los que hoy hacen parte las distintas sociedades y grupos humanos.

Se cuestiona la manera en que la escuela continúa perpetuando las formas de reproducción social y por ende las relaciones de clase existentes, mediante mecanismos y dispositivos que están pensados desde la estandarización y visión unilateral del saber y el conocimiento. El conflicto entre estos dos últimos tiene su origen en la manera como desde la epistemología se explican las características y formas de ser de cada uno. El análisis propuesto se enfoca hacia el camino que el maestro debe emprender para generar un diálogo entre ambas partes, con la finalidad última de contribuir a la construcción de una educación rural, que considere tanto el conocimiento que proviene de la ciencia normal, como los saberes propios del contexto campesino, que a partir de las necesidades y labores cotidianas se producen.

La propuesta formula la reflexión sobre la manera en que la educación rural, la escuela rural y el maestro deben adoptar una postura epistemológica que se adapte al cambio paradigmático, a través del empoderamiento del conocimiento, de los saberes y de nuevas formas de enseñanza y pedagogía, aquellas que se deben gestar a partir del reconocimiento de lo particular, lo local y lo identitario, desde propuestas propias, innovadoras y emancipadoras a nivel de currículo, didáctica y desarrollo comunitario.

Se abre el camino para que los maestros de la escuela rural, durante el ejercicio de la enseñanza, reconozcan la importancia no solamente del manejo y dominio de su disciplina, sino de las condiciones del contexto y de las carácterísticas propias del niño en relación con su entorno. Debe considerar los fines de su labor, en relación directa con las problemáticas sociales de la comunidad en que se encuentra inmerso. El trabajo debe enfocarse a generar mecanismos pedagógicos y propuestas de aula innovadoras que logren articular los conocimientos que imparte, las diversas interpretaciones que sobre los mismos se producen en las comunidades campesinas 
y la manera en que el niño los comprende, desde la utilidad que le otorga a los mismos de acuerdo a sus necesidades y expectativas de vida.

Se pretende abrir la escuela rural para que interactúe entre la ciencia y las culturas, la acción pedagógica entendida desde la capacidad de mediación y traducción intercultural que el maestro pueda desplegar. Se exige que en la escuela los individuos como sujetos culturalmente situados, deben ser respetados e incluidos a partir de su "subjetividad" individual y comunitaria.

Es importante que la comunidad académica y las personas en general despierten el interés y dirijan su mirada hacia el sector campesino, que tan olvidado ha estado durante décadas en nuestro país. Las iniciativas que germinan y se reproducen en los procesos educativos, son aquellas que generan trascendencia y permean las aulas y las escuelas, generando cambios a futuro en las relaciones sociales, de productividad y de identidad cultural en las comunidades campesinas. Si se plantean alternativas de mejoramiento y de cambio en las estructuras de desarrollo de las mismas, desde el abordaje de los conocimientos y de los saberes que son abarcados por los currículos de las escuelas rurales, seguramente los resultados y beneficios se darán en tiempo y espacio, al ser estos orientados y direccionados durante el proceso de formación de los niños y niñas de estas comunidades. 


\section{Referencias}

Acosta, M. (2010). El enclave de la escuela en el ambito rural. Bogotá: Universidad Pedagógica Nacional.

Althusser, L. (1989). Ideologia y aparatos ideológicos del Estado (notas para una investigación). En La filosofía como arma de la revolución. México: Siglo XXI Editores.

Barbetta, P. (2012). Breve paso por los debates clásicos. En colección becas de investigación de CLACSO, Ecología de los saberes campesinos: más allá del epistemicidio de la ciencia moderna. Reflexión a partir del caso del movimiento campesino de Santiago del estero vía campesina. Buenos Aires: CLACSO.

Bourdieu, P. (2005). La Reproducción. México: Fontamara.

Castro, S. (2007). Decolonizar la Universidad, la hybris del punto cero y el diálogo de saberes. En S. Castro (Ed). El giro decolonial, reflexiones para una diversidad episémica más alla del capitalismo global. (p.p 79-92). Bogotá: Siglo del hombre.

Chalmers, A. (1987). ¿Que es esa cosa llamada ciencia?. Madrid: Siglo XXI Editores.

Coley, G. (2008). La investigación sobre la escuela rural: una experiencia significativa. Cuadernos de psicopedagogía. 5: 107-120.

Crespo, P. (2006). Reflexiones sobre la educación popular: el caso de la capacitación campesina en proyectos de cooperación. Revista Iberoamericana de Educación. Columna de opinión. Dsiponible en http://www.rieoei.org/opinion25.htm

Cuervo, G. (1995). Génesis histórica y constitución de Bogotá como ciudad moderna. Bogotá: Corporación SOS Colombia-Viva la Ciudadanía.

DaSilva,T.(2001). Espacios deldentidad: Nuevas visiones sobreElcurrículo. Barcelona:Octaedro.

Delgado, A. (2011). Ética y política en la concepción de Educación Popular de Paulo Freire. Universidades: 50: 19-32.

De Sousa, B. (2009). Una epistemología del sur. La reinvención del conocimiento y la emancipación social. México: Siglo XXI.

García, E. (2005). Aprender investigando. Una propuesta metodológica basada en la investigación. Sevilla: Diada.

Kuhn, T.(1975). La estructura delas revoluciones científicas. México: Fondodecultura económica.

Lakatos, M. (1968). La crítica y el desarrollo del conocimiento. México: Fondo de Cultura económico.

Lander, E. (2000). La colonialidad del saber: eurocentrismo y ciencias sociales. Perspectivas latinoamericanas. Buenos Aires: CLACSO.

Mejía, M. (2001). La educación popular hoy y su concreción en las prácticas educativas formales y no formales. Trabajo presentado en el XXXII Congreso Internacional. Antigua, Guatemala. 
Mejía, M. (2011). Las teorías críticas y las pedagogías críticas. Fundamentos de la Educación Popular: hacia una agenda de futuro, Buenos aires: Diálogo de saberes.

Mejía, M. (2004). Leyendo las políticas educativas de la Globalización. Trabajo presentado en el Congreso de la CIEC. Chile.

Mignolo, W. (2003). Historias locales/diseños globales. Colonialidad, conocimientos subalternos y pensamiento fronterizo. España: Akal.

Novoa, A. (2013). www.mineducación.bov.co. Consultado en 28 de octubre de 2013. http:// www.mineducacion.gov.co/1621/article-168340.html.

Pulido,O.(2007).Currículo:discursoyPrácticadelaPedagogía.CuadernosdePsicopedagogía:26.

Quijano, A. (1998). Colonialidad del poder. Cultura y conocimiento en América Latina. Anuario Mariateguiano: 113-122.

Rodrigo, M. (2012). La construcción del concimiento escolar. Barcelona: Paidós.

Sánchez, S. (2010). Saberes escolares y conocimiento: conflicto entre pedagogías de la respuesta y las pedagogías de la pregunta. Praxis y Saber. (1): 77-101.

Walsh, K. (2005). Interculturalidad, conocimientos y decolonialidad. Ponencia presentada en el II encuentro multidisciplinario de educación intercultural. México.

Zamora, F. (2005). Sobre el quehacer de los docentes rurales. Huellas y búsquedas, una semblanza de las maestras y maestros rurales colombianos. Bogotá: Fundación Universitaria Monserrate.

Zamora, L. (2010). ¿Qué es lo rural de la educacion rural? el sentido y alcances de la categoría educación rural. Presentado en el Congreso Nacional de Educación rural. Medellín: 23.

Recibido: 16 octubre 2013

Aceptado: 19 noviembre 2013

Cómo citar:

Peña, C.M. (2014) Conocimiento escolar y saberes campesinos.

Encuentros y desencuentros en la escuela rural. Praxis Pedagógica, 15, 103-123. 